\title{
LA TEORÍA DEMPSTER-SHAFER EN LA APLICACIÓN DE MODELOS PREDICTIVOS ARQUEOLÓGICOS: EL CASO DE LA MINERÍA DEL COBRE EN TIERRA CALIENTE, MICHOACÁN, MÉXICO.
}

\author{
THE DEPSTER-SHAFTER THEORY IN THE APPLICATION OF \\ PREDICTIVE ARCHAEOLOGICAL MODELS: A CASE-STUDY OF COPPER \\ MINING IN TIERRA CALIENTE, MICHOACAN, MEXICO
}

\author{
Armando Trujillo \\ Estudiante de Doctorado. CNRS UMR 8096 Archéologie des Amériques, Université de Paris 1, \\ Email : Armando.Trujillo-Herrada@malix.univ-paris1.fr
}

Presentado el: 05/11/2012 - Aceptado 23/08/2013

\begin{abstract}
Resumen
En este trabajo se desarrolla un modelo predictivo arqueológico basado en la teoría probabilística de Dempster-Shafer. Se plantea a partir de un tema tan importante en el Occidente de México, como es el de minería del cobre durante el siglo XVI en la región de Tierra Caliente, Michoacán. La finalidad de este trabajo es exponer cómo esta herramienta enriquecida con datos de distintas disciplinas como la etnohistoria, geografía, arqueología, etc., trasciende en el quehacer arqueológico; esto nos plantea otro panorama de cómo las practicas van cambiando con el uso de nuevas herramientas de análisis, es decir, lo innovador se hace lo cotidiano por lo tanto en cierta manera indispensable.
\end{abstract}

Palabras claves: Sistema de Información Geográficos; Análisis espacial; Modelo predictivo; Teoría Dempster-Shafer

\begin{abstract}
In this work an archaeological predictive model is developed based on the probabilistic theory of Dempster-Shafer. The model arises from a very important topic in Western Mexico: copper mining during the 16th century. The aim of this work is to present how this tool, informed by various disciplines such as ethnohistory, geography, archaeology, etc., transcends the archaeological task. This presents us with another view of how practices are changing with the use of new tools of analysis, that is, what is innovative becomes everyday and thus indispensable.
\end{abstract}

Keywords: Geographic Information System; Spatial analysis; Predictive model; Dempster-Shafer theory 


\section{Introducción}

El desarrollo de la disciplina arqueológica siempre ha ido de la mano con otras disciplinas afines, como es el caso de la geografía, arquitectura, química, etc.; su conformación como disciplina se basa en muchos conceptos y modelos provenientes de otros campos de la investigación, por lo que de origen se podría considerar un área de conocimiento multidisciplinaria.

Una de estas innovaciones, incorporada paulatinamente por los arqueólogos en su quehacer científico, es la aplicación de los Sistemas de Información Geográfica (SIG), plataformas digitales enfocadas inicialmente en la geografía y después en otras disciplinas, en las que el componente espacial y territorial es significativo.

En la actualidad se usan para almacenar información, con el propósito de utilizarla en análisis espaciales que permitan ver patrones culturales en sus áreas de estudio. La habilidad de los SIG de combinar un amplio número de capas de información medioambiental y cultural ha permitido ampliar el panorama de la interpretación de los paisajes arqueológicos $\mathrm{y}$, con ello, el conocimiento de la estructura social de culturas pretéritas.

La aplicación de los GIS en arqueología despierta un creciente interés en círculos académicos por su potencial (Chapman 2003; Conolly y Lake 2006; Johnson 2006; Llobera 2003; Parcak 2009; Wescott y Brandon 2000; Wheatley y Gillings 2002). La razón es que "es un poderoso conjunto de herramientas para la recolección, almacenamiento, recuperación, transformación y visualización de datos espaciales del mundo real, esto propuesto a objetivos particulares" (Burrough y McDonnell 1998: 11; traducción del autor).

Este trabajo es un ejemplo de la aplicación de los SIG en la creación de un modelo predictivo arqueológico (MPA) dirigido a una actividad productiva, visto desde una perspectiva multidisciplinaria. Está enfocado a explorar su función como una herramienta útil en la creación de nuevas estrategias en el diseño de la prospección arqueológica en el Occidente de México.

Los modelos predictivos, principalmente desde sus primeras aplicaciones en la arqueología, han estado encaminados en dos sentidos: primeramente, como una estrategia en el diseño de la prospección arqueológica; en segundo lugar, como instrumento de gestión territorial del patrimonio arqueológico.

Su uso como herramienta de prospección se origina durante los años ochentas, en Estados Unidos, cuando se empiezan a utilizar los SIG para la ubicación de sitios con el propósito de proteger y conservar estos asentamientos.

Siguiendo esta tendencia de destinar los modelos predictivos a la localización de sitios arqueológicos, se instauró una línea de investigación importante para la arqueología, con los trabajos de Asch 1978; Dalla Bona 1994; Ebert 2000; Kohler 1988; Kohler y Parker 1986; Kvamme 1988a, 1988b, 1992, 2006; Warren 1990; Warren y Asch 2000, entre otros.

Dicha línea contribuyó a practicar una arqueología más regional, centrada en la búsqueda de patrones conocidos para después interpolarlos a espacios inexplorados, tratando de crear relaciones estadísticas significativas con los contextos naturales. 
Los modelos predictivos arqueológicos deben reposar sobre dos suposiciones fundamentales: primero, la decisión hecha por los pueblos antiguos con respecto a su lugar de establecimiento, estuvo fuertemente influida por las características medioambientales; segundo, hay que identificar los factores que influyeron directamente en estas decisiones en los mapas actuales de variación ambiental para el área de estudio. Considerando estas suposiciones, es posible desarrollar un modelo predictivo empírico para cualquier área en particular, mientras esta área haya sido muestreada por una prospección arqueológica (Warren y Asch 2000: 6).

En este sentido, el modelo planteado se encuadra en la primera suposición, el condicionante en la elección del asentamiento está influido por las características medioambientales. En el caso de esta propuesta, el condicionamiento no va dirigido a la subsistencia de un grupo de personas, sino a una actividad productiva, en este caso, a la producción minera del cobre.

\section{La Tierra Caliente de Michoacán}

La región por estudiar se ubica en el Occidente de México, al sureste del estado de Michoacán y comparte territorio con el noroeste del estado de Guerrero. Su nombre, Tierra Caliente, remite a sus altas temperaturas durante todo el año (Figura 1).

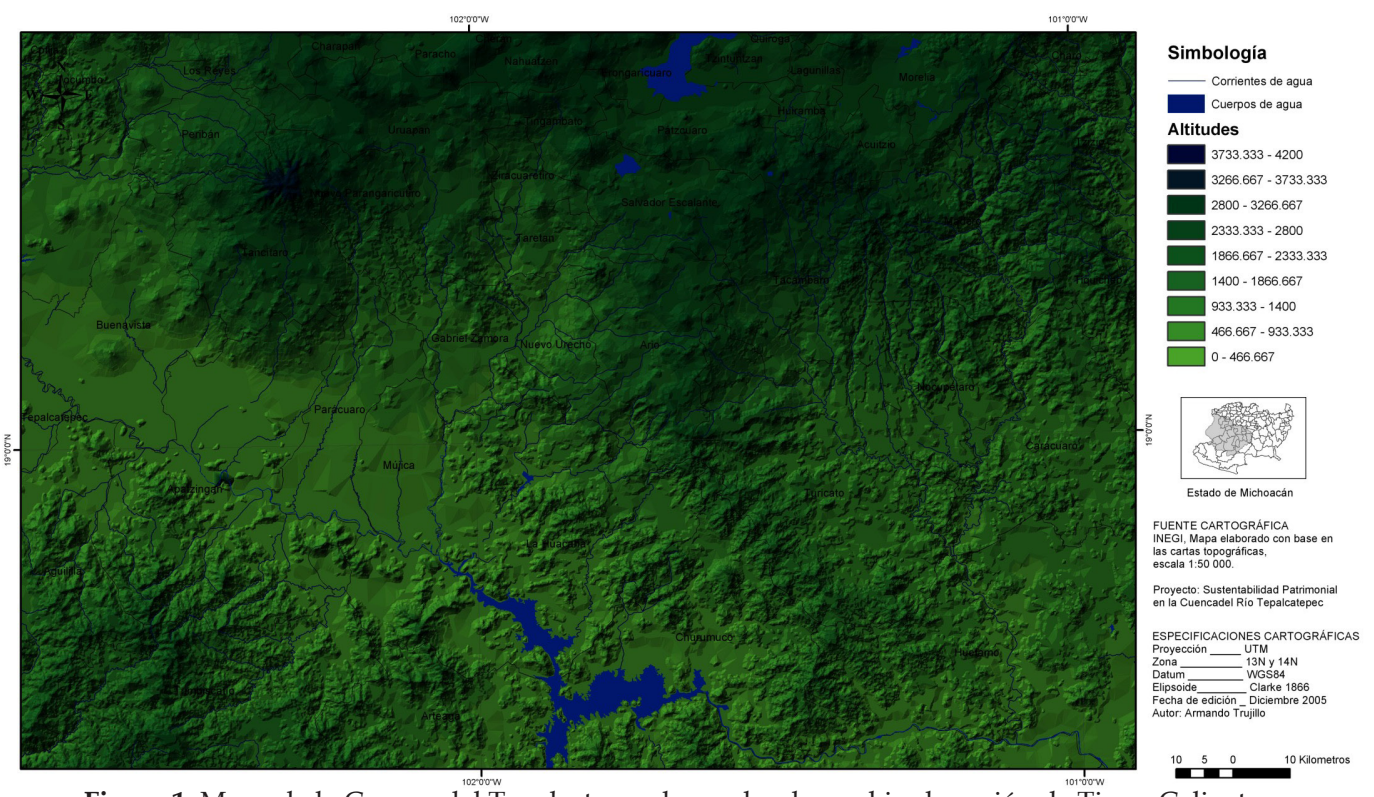

Figura 1. Mapa de la Cuenca del Tepalcatepec, lugar donde se ubica la región de Tierra Caliente.

Su historia se remonta a la época prehispánica, cuando grupos de pobladores lo eligieron como su territorio. Entre las filiaciones étnicas que se han identificado con más claridad para el periodo Posclásico (ca. 900-1521 d.C.), están los náhuatl, los tecos y los tarascos.

El auge de esta área se produce con la llegada de grupos chichimecas provenientes del norte de Michoacán -se cree que el último asentamiento durante su peregrinaje del linaje Uacúsecha es el sitio de Zacapu (Michelet 1995)- para asentarse a las orillas del lago de Pátzcuaro, donde fundaron su capital: Tzintzuntzan (Pollard 1987, 1993, 1994, 1995). 
Este grupo, denominado pueblo tarasco, alcanza su apogeo décadas antes de la llegada de los conquistadores españoles, durante la primera mitad del siglo XVI, con un dominio de gran parte de la Tierra Caliente, logrando controlar las redes tributarias y de intercambio de productos alimenticios y suntuarios (Barrett 1975).

En este contexto histórico-cultural tan distintivo, la minería del cobre en Tierra Caliente encuentra su lugar como una tradición practicada desde la época prehispánica hasta la actualidad, esta actividad productiva que puede ser diagnóstica para conocer el desarrollo cultural de los pueblos, así como su relación con los asentados en su entorno; además podemos plantear los vínculos culturales y su tipo de relación socioeconómica.

La metalurgia estuvo ligada en todos los ámbitos de la vida de los pobladores del continente, a tal grado que se presenta en las manifestaciones más íntimas, como es el ritual de la muerte: testigo de ellos son las estructuras funerarias, asociadas a suntuosas ofrendas, ya sea en el sitio de San Agustín, en Colombia (Duque y Cubillo 1979) o en el sitio mesoamericano de Monte Albán, en México (Blanton et al. 1999); el metal expresa esos lazos jerárquicos en el interior de la sociedad y la religión, pues vincula el mundo terrenal con el espiritual. La adopción de la metalurgia fue un elemento importante entre otros, más a un paso hacia la integración del desarrollo de sociedades complejas e intercambios regionales.

El análisis de la cultura material, de los objetos de cobre, va más allá de la descripción de sus formas y tamaños: permite una aproximación a cuestiones de la vida ritual, impregnada en la iconografía que adorna las piezas. Con la reserva de que todavía estamos lejos de conocer plenamente sus significados y el valor interpretativo en la cultura, pues la información con la que ahora se cuenta es todavía tenue y con muchos episodios aún obscuros para los arqueólogos e historiadores.

La historia de la minería en el Occidente mesoamericano surge en el Período Clásico (200 d.C. - 900d.C.); Hosler (1986, 1988a, 1988b, 1994a, 1994b, 1998, entre otros) señala que apareció espontáneamente en un primer período de dos que propone. Esto fue entre los años 600 d. C. - 1200/1300 d. C., en el área que ella define como "zona metalurgista del occidente" 1 .

Hosler (2005: 87) revela que durante este primer período se usó principalmente el cobre nativo, con el que se elaboró una variedad de objetos con vaciado a la cera perdida y trabajo en frío, seguido por el recocido. También hace referencia a que la elaboración de estos artefactos estaba pensada en destacar el aspecto visual y auditivo de sus concepciones sobre lo sagrado y, con esto, el reforzamiento de la clase dominante.

Durante el segundo período, comprendido entre el 1200/1300 d.C. hasta la llegada de los españoles, se experimentaron varios adelantos significativos tanto en el proceso de elaboración de piezas como en el material con el que eran creadas.

Los artesanos de Michoacán, Jalisco, Colima, el noroeste de Guerrero y la región sur del Estado de México empezaron a experimentar con una variedad de aleaciones de cobre, incluyendo las siguientes: bronce de cobre-estaño y cobre-arsénico, cobre plata, cobre oro, así como algunas aleaciones ternarias de cobre-arsénico-estaño y cobre-plata-oro, entre otras (Hosler 2005: 199). 
Éste fue un período en el que varios grupos participaron en su elaboración y distribución a escala macro-regional; pero, sin duda, la mayor influencia cultural y económica fue la del imperio tarasco².

Durante la historia de la minería prehispánica (900 años aproximadamente, entre los años 600 d.C. -1525 d.C.), acontecieron varios cambios a nivel tecnológico en la elaboración de las piezas, por lo que hemos utilizado el concepto de "chaîne opératoire" aunado al ciclo de producción y manufactura del cobre para poder contextualizar nuestro modelo.

El concepto de "chaîne opératoire", propuesto por André Leroi-Gourhan (1964: 164), y que se define como un mecanismo que permite poner en evidencia las diferentes "secuencias de fabricación del objeto arqueológico", señalando que "la técnica es al mismo tiempo gesto y herramienta, organizada en cadena a través de una auténtica sintaxis, que da, a la vez, a la secuencia operativa, su estabilidad y su flexibilidad" (traducción del autor).

Se trata de poner por delante el objeto arqueológico (el instrumento) como el criterio determinante en la chaîne opératoire. Se trataría entonces de una reproducción del gesto consumado, que es a la vez un objeto de búsqueda, de estudio y de explotación (en el marco de cualquier registro o excavación emprendido; Lenfant 2005) (Figura 2).

En este proceso minero, representado por la chaîne opératoire, hay un ciclo: extracción, fundición y manufactura de materiales. Para la comprensión de este ciclo se utilizan dos vías de información: la primera tiene que ver con la etnohistoria, disciplina encargada del estudio de documentos escritos durante la época colonial específicamente en este caso; la

\section{PROCESO DE FUNDICIÓN DE COBRE}

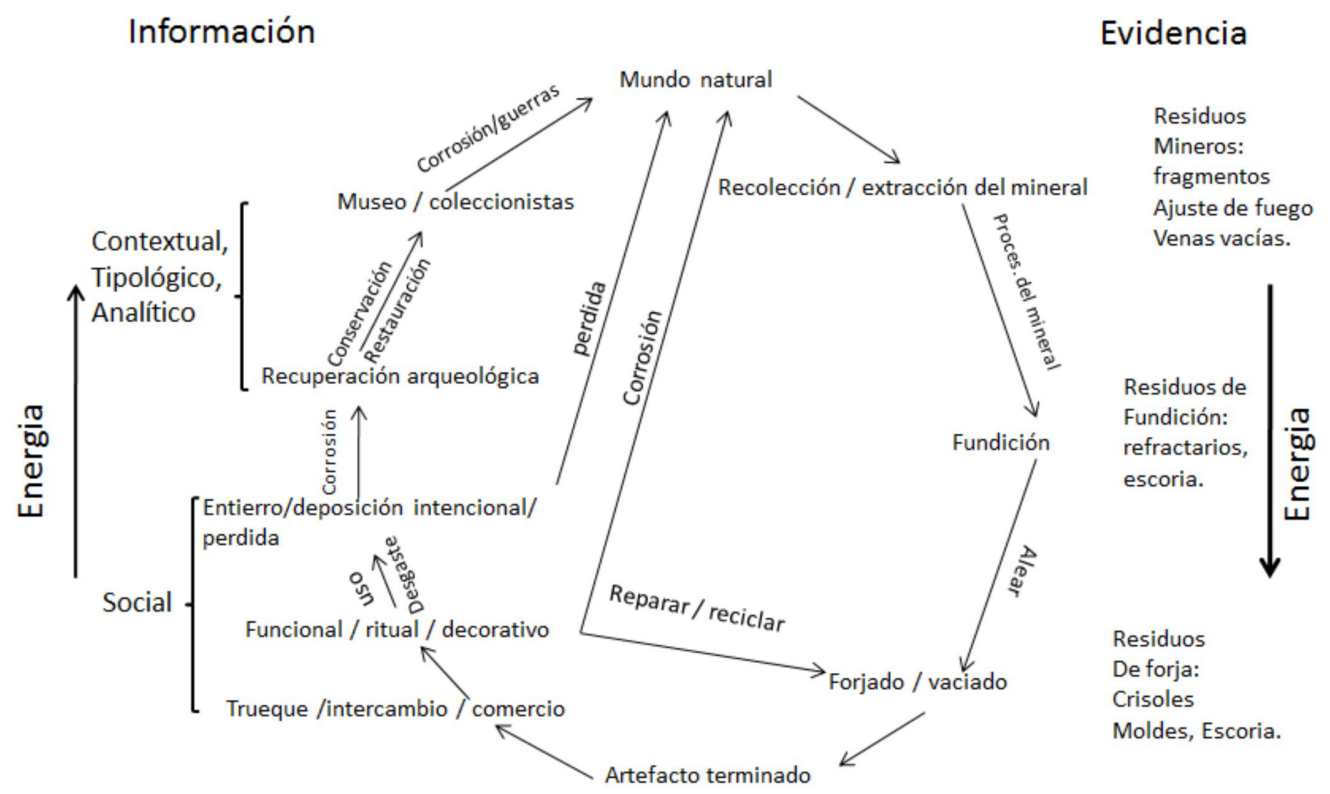

Figura 2. Ciclo de producción y trabajo del Cobre (Ottaway 1998: 88). El concepto de chaîne opératoire proporciona un marco capaz de vincular las prácticas materiales y sociales que intervienen en el proceso (Maldonado 2006: 97). 
segunda es la arqueología, una disciplina que estudia al hombre a través de la cultura material que yace en los asentamientos pretéritos. Estas dos disciplinas se complementan para arrojar datos que permitan entender los procesos sociales pasados.

Ahora se recurre a este concepto de chaîne opératoire para ilustrar la posición del modelo predictivo propuesto, que no pretende explicar la totalidad del proceso minero, sino aportar herramientas metodológicas para reducir los mecanismos de aproximación a este proceso de búsqueda de evidencias en el sentido espacial.

Este modelo se centra en la ubicación de asentamientos mineros con indicadores arqueológicos basados en la limpieza de las menas después de la extracción del material en minas cercanas a estos sitios; además se ha identificado en estos sitios evidencia de las prácticas de fundición, que quedan como vestigios en escoria localizada en estas áreas de actividad.

\section{La aplicación del modelo predictivo arqueológico en Tierra Caliente}

El modelo predictivo utilizado bajo la teoría Dempster-Shafer tiene como objetivo la localización de sitios arqueológicos relacionados a la producción metalúrgica, por tal motivo, se tuvo que empezar por plantear las bases para poder llevarlo a cabo.

De acuerdo con la metodología propuesta por Warren y Asch (2000), hay dos pasos a seguir para desarrollar un modelo predictivo: el primero es la creación de mapas de cobertura usando el SIG; el segundo es la caracterización y definición de los patrones espaciales de los sitios arqueológicos en los mapas de cobertura digital (Figura 3).

En este caso, el primer paso comenzó con el acopio de información de mapas originales. Afortunadamente la mayoría de los mapas que se manejan estaban en versión digital, a excepción de los de sitios con vestigios mineros y minas coloniales, los cuales se tuvieron que digitalizar.

En este apartado se realizaron ejercicios de cartografía histórica, ya que se desconocía la ubicación exacta de algunas de las minas; pero gracias a la combinación de descripciones geográficas y mapas en fuentes coloniales, rasgos naturales distinguibles en el paisaje, prospección y datos actuales, fue posible ubicar estos sitios de extracción minera.

Estos datos fueron sistematizados y clasificados en dos tipos: primero, los arqueológicos, que consisten en el registro de sitios con evidencias de actividad minera y las minas que fueron explotadas durante este período y otras que se recopilaron en informes actuales que posiblemente fueron utilizadas también durante esta época. El segundo tipo de datos son mapas con información medioambiental, en la que están incluidos la hidrología, la geología, la vegetación, la topografía, etcétera. Estos dos tipos de datos ayudaran a desplegar otros para realizar el ejercicio propuesto.

La información de los sitios arqueológicos mineros proviene de distintas fuentes como se había mencionado anteriormente: la primera es la más detallada y completa por el objetivo de la investigación; se trata de los trabajos realizados por la doctora Hosler (1986, 1988a, 1988b, 1994a, 1994b, 1997, 1998, 2000, 2002, 2004, 2005 y 2009), quien realizó una prospección 


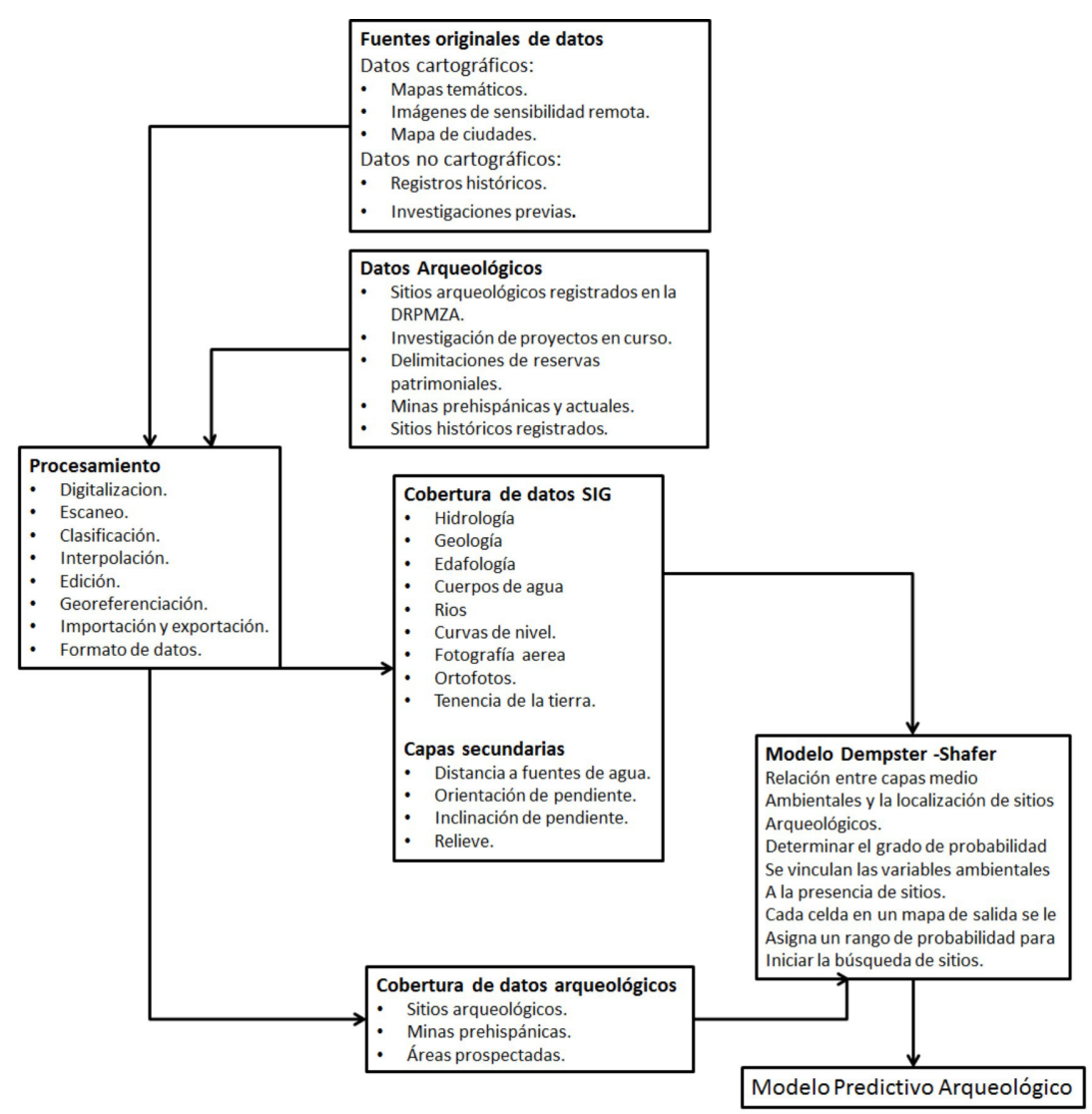

Figura 3. Diagrama de flujo de las etapas del modelo predictivo arqueológico.

en lo que se denomina "el cinturón de cobre", particularmente al sur del río Balsas, en la región de Coyuca, Altamirano, Zirándaro y Placeres del Oro.

Su trabajo de prospección es enriquecedor no sólo por la ubicación de algunos sitios de extracción y fundición (Agua Fría, Cerro del Chivo, El Manchón, Los Herreros, El Ticato y Santa Teresa), sino también por los datos que caracterizaron la ubicación de estos sitios, lo cual nos permitió delinear las variables para el modelo.

Otra fuente está constituida por los informes Dirección de Registro Público de monumentos y Zonas Arqueológicas del Instituto Nacional de Antropología e Historia (DRMPZA-INAH), que indican la existencia de sitios registrados con esta actividad, datados relativamente para épocas tardías, que también presentan evidencia de prácticas mineras; entre éstos están: Los Montones, El Huicumo, La Campana y Santo Domingo, registrados por distintos proyectos y en temporalidades distintas (que más adelante explicaremos, así como las características de cada sitio) (Grave 1997; Grave et al. 2000; Pulido et al. 1997).

Se agrega a la lista el sitio localizado en las cercanías de los actuales poblados de Santa Clara del Cobre y Apopeo, denominado Itziparátzico, donde se puede suponer actividades extractivas por la escoria encontrada cerca los manantiales contiguos al sitio (Maldonado 2002, 2006). 
El último sitio arqueológico agregado a esta lista es Jicalán el Viejo, investigado por Roskamp et al. (2001) desde dos ópticas: la etnohistoria y la arqueología. Sus interpretaciones a partir de fuentes coloniales se han corroborado en gran medida con trabajos de prospección en el sitio.

El registro total de sitios en la región de Tierra Caliente, asciende a más de 130 sitios de los cuales 12 sitios se tienen evidencias de actividades mineras. Los sitios están distribuidos en los 7 municipios de Tierra Caliente, estos sitios tiene ocupación que varía del periodo preclásico (200 a.C.) hasta el periodo colonial (posterior al 1521 d.C.)

\section{Distribución de minas de cobre}

Para conocer acerca de los comienzos de la minería del cobre en la región así como de las principales minas que jugaron un papel en el desarrollo de esta actividad durante el siglo XVI se usaron principalmente tres fuentes de información: los datos arqueológicos, fuentes documentales del siglo XVI y reportes mineros actuales. El número de minas registradas asciende a 54, y en su mayoría fueron inventariadas por el Consejo de Recursos Mineros.

En esta búsqueda entonces se involucran las fuentes coloniales con datos de minería actual, por ejemplo: las minas ubicadas en el actual municipio de Churumuco, las de "Puerto de Mayapito", que fueron ubicadas en 1982, como parte de un estudio topográfico preliminar por el ingeniero Óscar Mendoza y Ernesto Calvillo; se ubican aproximadamente a cinco kilómetros del poblado de Nuevo Churumuco.

Estas minas también fueron localizadas por la doctora Grinberg (1990: 25) durante un recorrido que hizo por la zona del cerro del Mayapito con el propósito de ubicar el sitio documentado en el Lienzo de Jicalán, ella logró ubicar dos minas que estaban hundidas desde la época prehispánica, gracias a "terreros" que se forman por la acumulación de los desperdicios de la actividad minera.

También se recopilaron datos de otras minas coloniales como Cocian, Inguarán, Sinaguan, Tepequcuilco y Coalcoman, entre otras. Además de los datos ubicados en fuentes coloniales, agregamos otros actuales de minas que pudieron ser explotadas durante esa temporalidad y se cotejaron con trabajos arqueológicos (e.g. Hosler 1996: 1819-1824), tomando como referencias investigaciones citadas anteriormente.

El medio ambiente constituye el escenario de los procesos culturales; los datos relacionados con éste se conjugan para crear estadísticamente relaciones significativas que hacen de la descripción geográfica una predicción de patrones de asociación entre naturaleza y cultura.

En el caso del estudio predictivo que se plantea, se decidió incorporar datos ambientales que permitan encontrar tales relaciones significativas: capa de curvas de nivel, capa de ríos permanentes y semipermanentes, capa de cuerpos de agua y capa de yacimientos mineros de cobre.

Los datos incorporados provienen esencialmente del Instituto Nacional de Estadística e Informática (INEGI), y están representados a una escala 1:50 000., la adquisición de estas capas de datos aporta información parcial para el modelo, éstas y las variables dependientes forman las bases para los productos derivados de ellas. Por ejemplo: la capa de curvas de nivel permite crear el modelo de elevación digital y, con esto, las superficies de costo. 


\section{La caracterización de los sitios mineros entorno de las minas}

Las características comunes de los sitios considerados permiten generar un patrón de comportamiento en el momento de asentarse en un espacio geográfico. La elección de paisajes particulares presenta elementos diagnósticos, utilizados en la predicción de espacios, los cuales primero se describen para después generar estadísticamente escenarios óptimos para la presencia de sitios que tengan como principal actividad los procesos mineros.

Las variables comunes en la elección de espacios son principalmente cuatro: la cercanía de corrientes de agua permanentes o semipermanentes, además algunos otros sitios están asociados a cuerpos de agua como manantiales (como el sitio de Itziparátzico); esta variable es clave en el proceso de limpia de la mena, ya que "la mena necesita lavarse muy bien antes y después de ser molida" (Hosler 2004: 345). La cercanía con afluentes de agua también se ve presente en documentos coloniales, como el Lienzo de Jicalán, que agrega información de las rutas tributarías y la distribución de los sitios cerca de los principales afluentes como el río Balsas y el Tepalcatepec, la región de la presa del Infiernillo, además de afluentes secundarios como el río Cupatitzio, en caso específico de la ruta Jicalán / Cundembaro (Roskamp et al. 2001: 62-63 y 135-136).

La segunda variable en común para la ubicación de sitios que cumplieran alguna labor de actividad minera fue su cercanía a los yacimientos mineros, "ya que los minerales de mena son bastante pesados y es poco probable que los antiguos mineros los hubieran transportado a distancias considerables" (Hosler, 2004: 339). Se estima una distancia no mayor a dos kilómetros entre el yacimiento minero y el sitio arqueológico. Esta constante también puede observarse en las fuentes coloniales (Acuña 1984, 1987; Barret 1981; De la Torre Villar y Navarro de Anda 1984; Roskamp 1999).

La tercera variable consiste en el análisis estadístico que realizamos previo a la creación del MPA. Este análisis consistió en buscar patrones estadísticos con los datos que ya contamos. Durante el análisis se pudo establecer que los sitios arqueológicos en la región, no solo se encuentran a una distancia menor de dos kilómetros respecto a las minas de cobre, sino que además la cercanía entre ellos no es mayor a cinco kilómetros. Esta forma en que están dispuestos los sitios, nos muestra una distribución bien relacionada, posiblemente para una explotación de recursos más eficaz.

Una cuarta variable que encontramos en el patrón de asentamiento de sitios mineros, es su ubicación sobre pendientes muy suaves, es decir, pendientes no mayores a 8 grados. La razón de realizar el menor costo de energía en la edificación de estructuras, de esta manera se evitan trabajos de nivelación, así como construcción de plataformas donde estarían ubicadas las residencias habitacionales.

Los anteriores datos sistematizados permitieron proponer que los modelos geográficos dentro de la estadística espacial han pasado de ser un rasgo descriptivo a ser un rasgo predictivo, creando modelos de optimización en la investigación, que se van enriqueciendo conforme avance el estudio, nutriendo paralelamente este modelo. 


\section{Los productos y subproductos de la base de datos}

El acopio de información tanto cultural como natural sentó las bases para la creación de una plataforma sistematizada de donde se pudieran desprender subproductos informáticos para la conformación de información necesaria en el modelo predictivo. Estos subproductos fueron creados en dos plataformas de análisis según fuera conveniente: Arcview (9.0) e Idrisi Kilimanjaro®.

Los datos derivados de la base inicial de información fueron: elevación (modelo digital de elevación), pendiente (slope) y el modelo de orientación de pendientes (aspect), estos dos últimos derivados del MDE.

\section{Metodología}

Se siguió la metodología propuesta por Anaya (2001) para poder realizar modelos predictivos, que inicia con la evaluación de la evidencia arqueológica existente, con la intención de interpolar grados de probabilidad que apoyen una de las tres hipótesis rectoras de este modelo: presencia de sitio, ausencia de sitio y ausencia-presencia de sitio.

Subrayemos que el modelo de Dempster-Shafer, también conocido como "el valor de evidencia", es un modelo matemático-estadístico que tiene como objetivo la evaluación del grado de probabilidad, la cual se conoce por distintos niveles de certidumbre o incertidumbre de que un evento ocurra. Es decir: evalúa el grado en que la evidencia provee soporte concreto para una hipótesis (creencia) y el grado en que aquélla no refuta la hipótesis (plausibilidad).

El proceso se realizó con el software IDRISI Kilimanjaro® 14.01, el cual incluye herramientas de análisis probabilístico compuesto por un complejo conjunto de cálculos que complementan el módulo BELIEF, módulo de análisis utilizado para la aplicación de la teoría Dempster-Shafer.

Siguiendo con la evaluación de la evidencia arqueológica, es necesario establecer las líneas de información que apoyen una de estas tres hipótesis planteadas. Las evidencias relacionadas con la probabilidad de que existan sitios arqueológicos mineros son sitios mineros conocidos en el siglo XVI, distancia en torno de las minas de cobre, afluentes de agua, grado de pendiente y la cercanía a sitios arqueológicos habitacionales.

\section{Incorporación de superficie de fricción en el costo de energía}

El paisaje terracalenteño se caracteriza por una accidentada topografía en la que destacan el cambio de niveles altitudinales, que varían entre 300 y 2000 m.s.n.m., dando pie a un amplio rango de pendientes, por lo que se ha decidido incluir en el análisis superficie de fricción y no sólo la distancia euclidiana.

La fricción anisotrópica se define por las diferencias en el gasto de energía de acuerdo con el grado de pendiente que se recorre; por ejemplo: es diferente la cantidad de energía que se utiliza cuando se recorre una planicie que cuando se atraviesa una barranca o se asciende una montaña. 
La fórmula propuesta por Schneider y Robbins (2009), nos ayuda a estimar la fricción anisotrópica, donde la relación entre pendiente y fricción tomará la forma de una curva que se puede expresar con la siguiente ecuación binominal: $Y=\left[.031 \mathrm{X}^{2}\right]+[-.025 \mathrm{X}+1]$. Donde $\mathrm{Y}=$ la fricción; $\mathrm{X}=$ la pendiente; $\mathrm{y} .031$ y -.025 las constantes derivadas de ajustar la curva a los valores obtenidos con las observaciones empíricas.

Los resultados obtenidos de este proceso de álgebra de mapas son una imagen con el costo de energía en torno de las minas de cobre con el propósito de afinar el modelo en cuanto a las distancias de los sitios mineros (Figura 4).

Este mismo proceso se realizó para determinar la proximidad a fuentes de agua, usando la fricción anisotrópica se crearon buffer a partir de los datos vectoriales de río y de cuerpos de agua.

\section{La combinación de líneas de evidencia en Dempster-Shafer usando BELIEF}

BELIEF es una herramienta en la que se pueden mezclar las líneas de evidencia al aplicar las reglas de combinación basadas en la teoría de Dempster-Shafer. Los datos de entrada corresponden a lo que llamamos asignaciones de probabilidad básica (APB) las cuales indi-

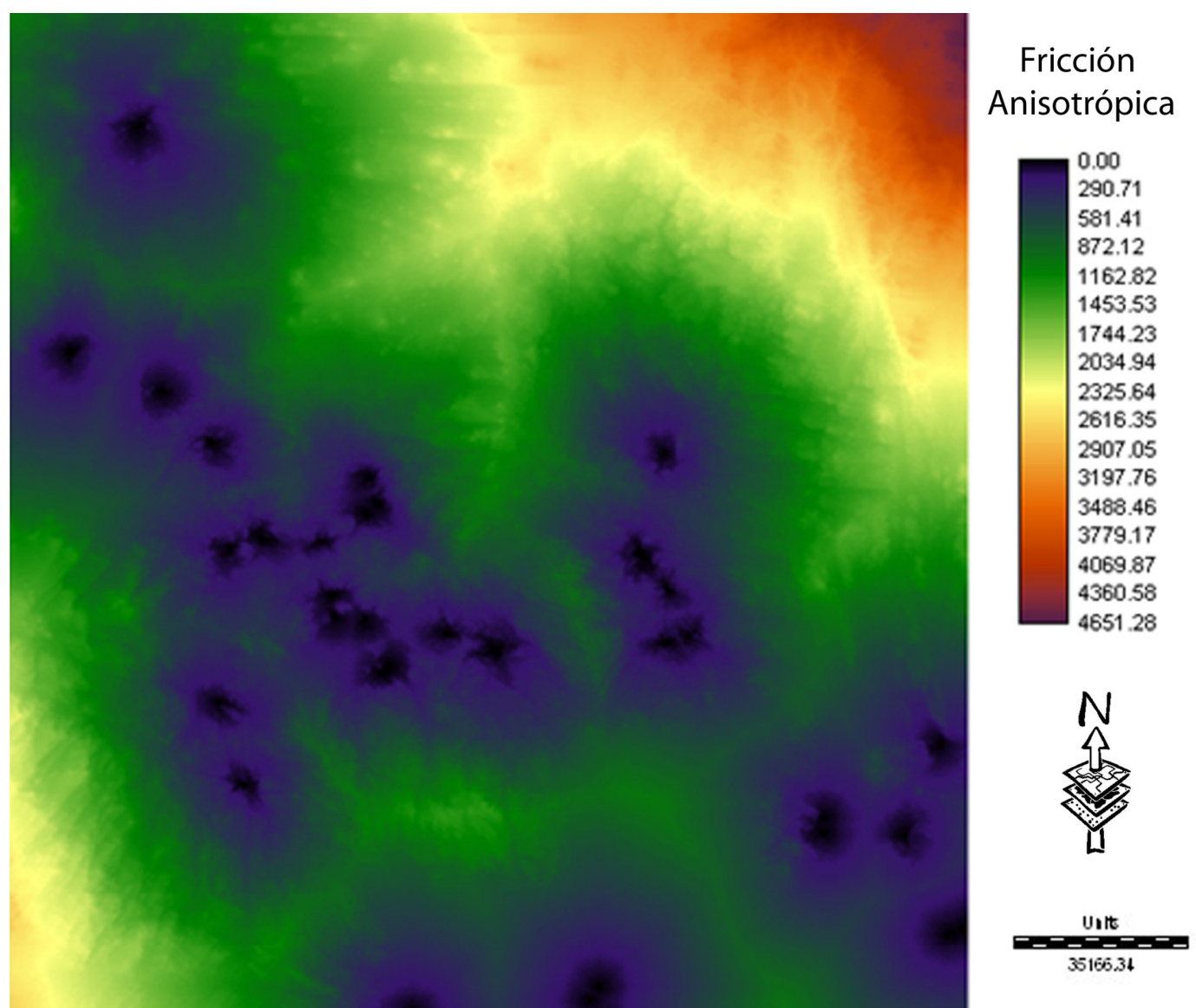

Figura 4. Fricción anisotrópica representada alrededor de las minas de cobre en la región de estudio. 
rectamente relacionan pruebas que apoyan alguna de las hipótesis del marco de decisiones, donde se encuentran las posibles hipótesis contenidas, apoyadas por las líneas de evidencia; éstas, a su vez, son las que construyen una base de conocimiento. Se pueden extraer imágenes de creencia, plausibilidad e intervalos de creencia por cada hipótesis planteada.

Para iniciar el análisis de los datos, se plantean las variables por utilizar para la creación de las líneas de evidencia de acuerdo con los paisajes característicos en los que se albergan los sitios mineros.

Estas variables son seleccionadas de acuerdo con las evidencias arqueológicas registradas sistemáticamente en el área de estudio y los criterios de estimación de distancia provienen de la relación estadística que encontramos en la creación de mapas con tales variables; esto con la finalidad de que la estimación nos proporcione información más significativa.

Variables aplicadas para elaborar las líneas de evidencia

$\begin{array}{ll}\text { Variables } & \text { Parámetros } \\ \text { Minas Distancia } & <=2000 \mathrm{~m} \\ \text { Sitios_min Distancia } & \quad<=5000 \mathrm{~m} \\ \text { Cuerpos_agua Distancia } & <=1000 \mathrm{~m} \\ \text { Pendiente } & <=8 \text { grados }\end{array}$

Lo siguiente en la conformación de la base de conocimiento es agregar las líneas de evidencia, para lo cual se ingresa en Añadir nueva línea de evidencia (Add line of evidence) y se va incorporando cada imagen de probabilidad como "agua-nositio", y se señala qué hipótesis apoya; en este caso, a la que define la ausencia de sitio (No-Sitio), se asignó también un nombre a cada línea de investigación para poder identificarlas en la ventana general. Estas líneas de evidencia son convertidas en imágenes de probabilidad dirigidas a alguna de las tres hipótesis (Tabla 1).

\begin{tabular}{|l|l|l|}
\hline Caption & Image Name & Supported Hvpothesis \\
\hline Sitios mineros & Sitio sitio & Ipresencia de sitiol \\
\hline Minas & Minas nositio & Iausencia de sitiol \\
\hline Pendiente & Pendiente sitio & Ipresencia de sitiol \\
\hline Orientación de pendiente & Aspect sitio & Ipresencia de sitiol \\
\hline Distancia a cuerpos de aqua & Aqua nositio & Iausencia de sitiol \\
\hline
\end{tabular}

El siguiente paso es construir la base de conocimiento (build knowledge base). En este proceso se crean las definiciones básicas de probabilidad para las tres hipótesis; esta base se elabora en Analysis / build knowledge base. Una vez completado este proceso se obtiene el resumen (summary) en el menú de Analysis / Extract summary. La obtención del resumen nos proporciona mapas de creencia, plausibilidad e intervalo de creencia, de acuerdo con la hipótesis que elijamos.

Para este análisis es indispensable conocer la creencia, plausibilidad e intervalo de creencia para la hipótesis que apoya la existencia de "Sitio": con estas imágenes podemos visualizar los resultados de la combinación de las líneas de evidencias propuestas y las hipótesis que las apoyan. 


\section{Resultados del modelo Dempster-Shafer y la producción de mapas generados}

Los resultados obtenidos en este proceso probabilístico se presentan en tres tipos de imágenes a evaluar; la más importante en este caso es la que denota las áreas con alta probabilidad de presencia de sitios con actividades mineras. Para esto se desplegaron dos de las tres opciones del módulo Dempster-Shafer: las que visualizan las opciones de creencia e intervalo de creencia.

La primera imagen de tipo creencia (Belief) representa el apoyo total a una hipótesis, se visualiza en una imagen con tonalidades acordes con su valor probabilístico de 0 a 1.0 La cercanía al valor 1.0 representa un mayor grado de probabilidad de encontrar sitios de actividad minera (Figura 5).

Se ha realizado la estimación de área de investigación total en respecto del área que ocupan los polígonos con mayor probabilidad de sitios mineros y los resultados son los siguientes (tabla 2):

El porcentaje de área con alta probabilidad de sitio se estima en un $4.29 \%$. Estas áreas seleccionados se exportaron a ArcGis ${ }^{\circledR}$ v.9.0 en un proceso previo que selecciona un rango

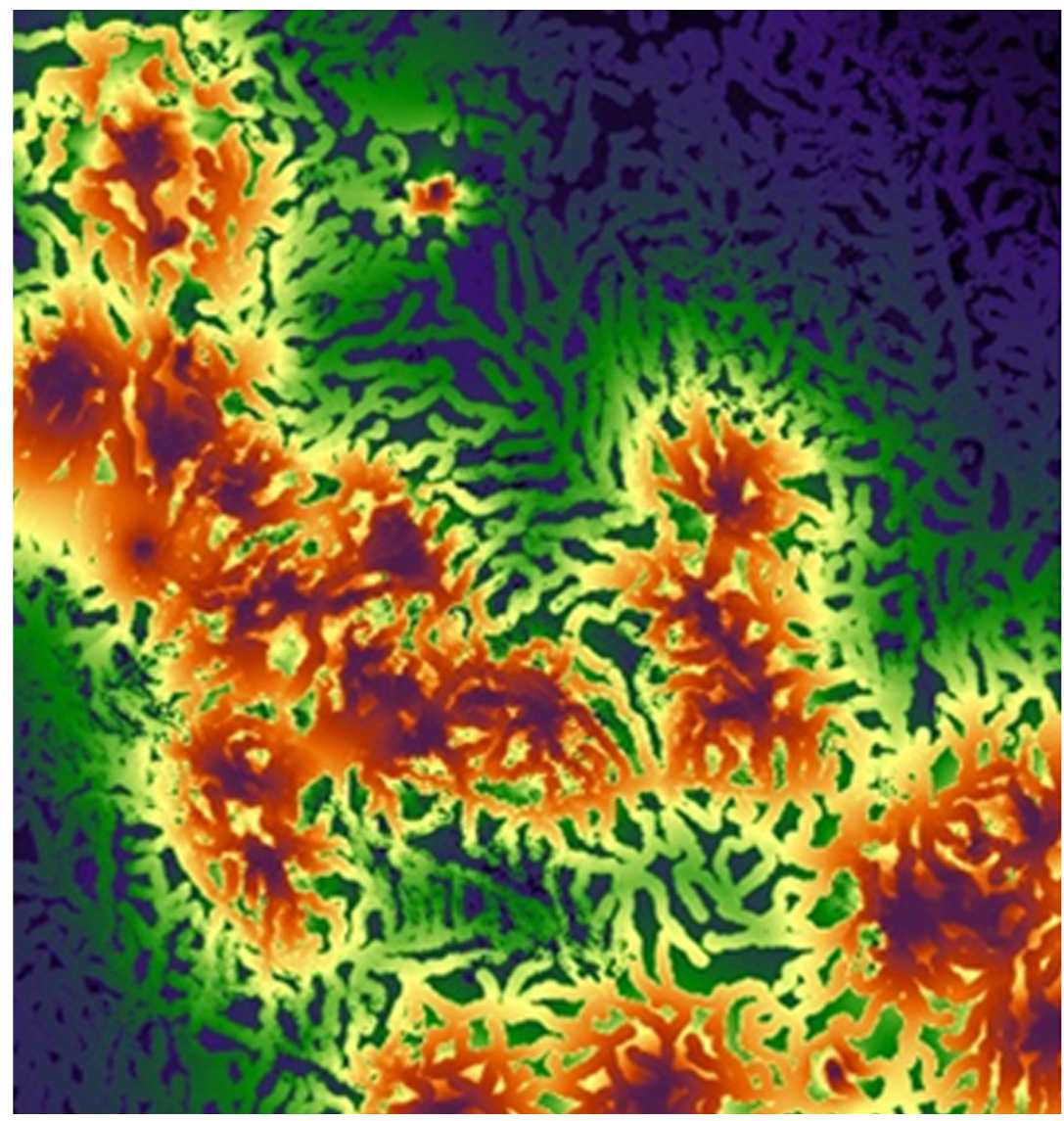

\section{Grado de Creencia}
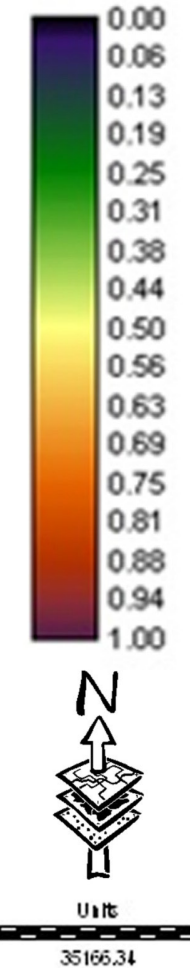

Figura 5. Mapa de creencia que apoya la hipótesis de sitios arqueológicos. 


\begin{tabular}{|l|l|}
\hline Categorías & $\begin{array}{l}\text { Kilómetros } \\
\text { cuadrados }\end{array}$ \\
\hline 0 (No Sitio) & 32129.04030 \\
\hline 1 (Sitio) & 1441.68538 \\
\hline Total & 33570.7256 \\
\hline
\end{tabular}

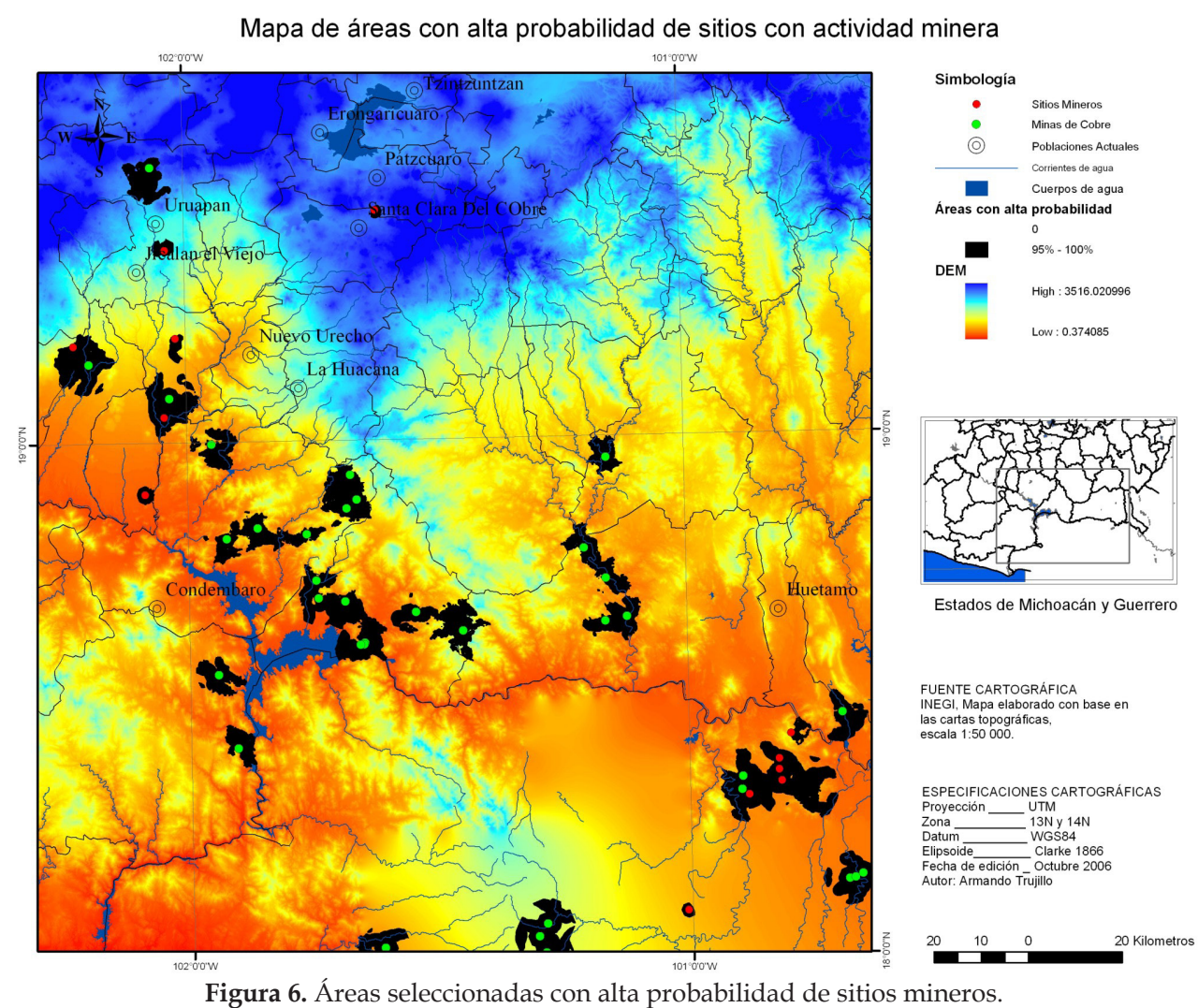

entre el 95\% y el 100\% del área con alta probabilidad3, lo que permite visualizar las áreas con mayor facilidad en relación con las minas de cobre y los sitios mineros con los que ya contaba (Figura 6).

Como se puede observar en el mapa de áreas con alta probabilidad, hay una relación estrecha entre las minas de cobre y las áreas de alta probabilidad. Recordemos que ésta era una de las variables más importantes en la búsqueda de estos sitios.

También existe una relación constante entre los sitios mineros y las áreas seleccionadas. Esto se debe a que aquéllos compartirían escenarios ideales donde confluyen las mismas líneas de evidencia planteadas para la hipótesis de Sitio.

Las características de la figura 6 muestran que las áreas están ubicadas principalmente en las partes bajas de $\mathrm{MDE}$, con cercanías a los principales afluentes de la región (i.e. río Tepalcatepec), donde están los sitios registrados con evidencia de esta actividad, asentados preferentemente en pendientes suaves. 
Hay que destacar en este modelo la acertada elección en la incorporación de la fricción anisotrópica en comparación con la distancia euclidiana, con lo que se mesuró el gasto de energía en relación con la accidentada topografía de la región de estudio.

Este ejercicio plantea la posibilidad de restringir espacios a la hora de toma de decisiones en la estrategia de prospección arqueológica: por un lado, muestra las zonas con más alta probabilidad de presencia de sitios; estos polígonos, debidamente geo-referenciados y con una estimación en costo de energía, permitirán reducir de forma considerable los periodos de campo, los costos económicos y de personal, optimizando recursos que pueden ser utilizados en otras etapas de la investigación.

La segunda imagen seleccionada fue la de intervalo de creencia, que muestra las zonas donde se requiere adquirir más información arqueológica. Es decir, en las que los datos con los que cuenta el modelo no son concluyentes para aseverar presencia o ausencia de sitios mineros, por lo que es necesario considerar estás áreas en el diseño de prospección con el propósito de obtener más datos que puedan servir para nutrir el modelo predictivo (Figura 7).

Las áreas seleccionadas donde se requiere hacer muestreos van del rango de .85 al .98. Es necesario destacar que para la adquisición de información en este caso no se contó con datos mineros para esta región, debido a la falta de investigaciones en un sentido general.

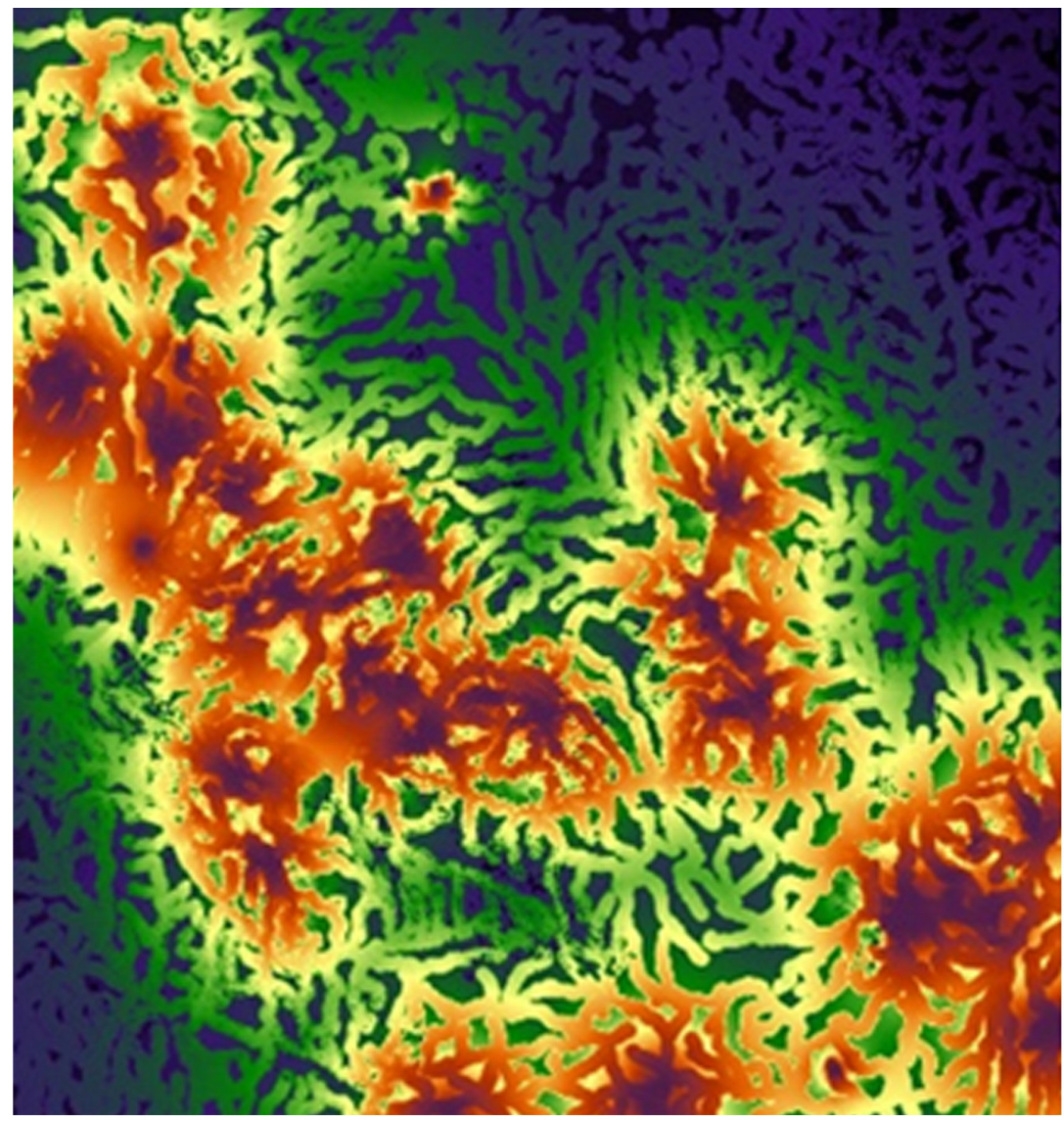

Grado de Creencia

Figura 7. Mapa de grado de creencia de intervalo.

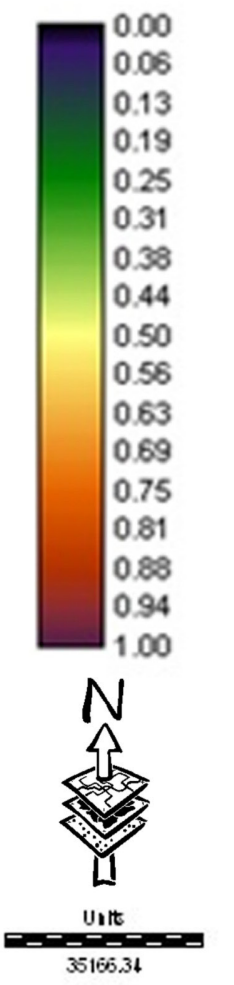


En mi opinión, ésta es la ventaja más importante de utilizar un modelo predictivo basado en la teoría Dempster-Shafer, la posibilidad de tener varias respuestas graficas en grados de probabilidad de una misma problemática.

El beneficio que ofrece este modelo es la oportunidad de jerarquizar zonas de recorrido, reducir estas áreas considerablemente, estimar costos de los recorridos de acuerdo con las extensiones planeadas, reducir el personal u ocuparlo en áreas más relevantes para la investigación, y en el sentido general, reducir recursos económicos. Otra de las ventajas de trabajar en plataformas SIG es la pronta incorporación y actualización de datos. La última incorporación de éstos al modelo predictivo actual fueron los referentes al registro de sitios arqueológicos llevados a cabo por proyectos de la Dirección de Salvamento Arqueológico y por el "Proyecto Sustentabilidad Patrimonial de la Cuenca del río Tepalcatepec" (Trujillo 2011), en su mayoría sistematizados y almacenados en esta investigación.

La base de datos consta de todos los sitios arqueológicos registrados hasta la fecha en la región de estudio; la información que contienen es el nombre del sitio, su ubicación (UTM), municipio en que se localiza, tipo de sitio y cronología estimada. No se cuenta con toda la información de gran parte de los sitios, especialmente el tipo y la cronología estimada, debido al deterioro ambiental y al saqueo constante; esto dificulta la investigación arqueológica.

Se puede saber, sin embargo, que estos sitios pudieron estar asociados a periodos de ocupación relevantes para este estudio; además su existencia pudiera relacionarse con actividades mineras. Con esto no se asegura que los sitios arqueológicos registrados cercanos a las minas tuvieran actividades mineras, pero no hay que descartar esta posibilidad.

Esta incorporación de datos ayuda a ir directamente a los sitios comprendidos en las áreas en las que, a partir de las variables y líneas de evidencias planteadas, se cree que es más viable encontrar sitios con actividad minera. Lo que permite acotar significativamente las zonas de prospección arqueológica.

\section{Consideraciones finales}

La función de paisaje minero en Tierra Caliente se expresa en el Modelo Predictivo Arqueológico (MPA) de una manera dinámica e interactiva. La conjunción de rasgos físicos del ambiente natural y la información arqueológica permitió rastrear patrones de correlación espacial, susceptibles de ser evaluados para su caracterización y predicción de evidencia arqueológica.

Tales elementos, que participan en mayor o menor grado, posibilitaron entrever ese complejo proceso de interacción impulsado en este caso por la minería del cobre, involucrado en una chaîne operatoire a distintos niveles socioculturales de la población, donde cada actor tiene una participación diferenciada, pero a su vez se conjuga en las labores de producción, distribución y uso de artefactos de cobre.

Las tareas realizadas por los distintos actores en la minería en muchas ocasiones pueden ser rastreadas en el registro arqueológico. Esto depende de la calidad de la información y de su alcance interpretativo en relación con otros datos, no siempre propios de la arqueología. 
Con este esquema de trabajo se planteó la idea de crear medios técnico-metodológicos para elaborar un diseño estratégico de prospección, que pudiera ser aplicado a distintas problemáticas sociales con modificaciones menores.

Los mayores beneficios en la creación y aplicación de esta metodología están enfocados a la optimización de medios económicos, de uso de personal y tiempo, con la característica de facilitar la aproximación a los procesos observables con un enfoque espacial de tipo multiescalar, lo que permite evaluar los procesos de la investigación desde distintos niveles no sólo espaciales, sino también interpretativos, si así se desea.

\section{Notas}

1.La "zona metalurgista del occidente" comprende los actuales Estados de Jalisco, Michoacán, Nayarit, Colima y el sur de Sinaloa, así como el norte de Guerrero y partes del Estado de México. En la parte sureste del actual Estado de Michoacán, donde se localiza el cinturón del cobre, una prolongación de yacimientos mineros con ricas menas de cobre y otros minerales. 2 El imperio Tarasco reinó las tierras altas de la región centro-occidente de México a inicios del periodo postclásico medio, fue el segundo imperio más importante después del Azteca. Los tarascos plasmaron su historia en un documento denominado La Relación de Michoacán (Pollard 1993). 3 La elección del rango en porcentaje del 95 al 100\% está en relación a los grados de confiabilidad de la evidencia, es decir, este rango puede ser ampliado o reducido de acuerdo a los objetivos del proyecto y su financiamiento. Recordemos que entre más amplio sea rango, mayor es el área a investigar y las probabilidades de encontrar vestigios arqueológicos va en disminución mientras nos alejamos al valor 1.0.

\section{Bibliografía citada}

Acuña, R.

1984. Relaciones Geográficas del Siglo XVI. Antequera, II Tomos. Universidad Nacional de Antropología e Historia, México.

1987. Relaciones Geográficas del Siglo XVI: Michoacán. Universidad Nacional de Antropología e Historia, México.

Alcalá, G.

1988. La relación de Michoacán. Ed. Cien de México, Secretaría de Educación Pública, México.

Anaya Hernández, A.

2001. Site Interaction and Political Geography in the Upper Usumacinta Region during the Late Classic: a GIS Approach. Bar, International Series 994, Oxford.

Asch, D.

1978. Predictive Modeling of Archeological Site Location in an Illinois Upland Prairie Region: A Systematic Survey of the Montgomery County Panhandle. Unpublished manuscript, submitted to the Illinois Deparment of Conservation, Springfield, Illinois, Northwestern University Archeological Program, Kampsville, Illinois.

Barrett, E.M.

1981 The King's Copper mine, Inguarán in New Spain. The Americas 38 (1): 1-29. 
Blanton, R., M. Feinman, S.A. Kowalewski y L.M. Nicholas

1999 Ancient Oaxaca: the Monte Albán State. Cambridge University Press, Cambridge y New York.

Burrough P. y R. Mcdonnel

1998 Principles of Geographical Information Systems. Oxford Univiversity Press, Oxford.

Chapman, $\mathrm{H}$.

2003 Rudston 'Cursus A' - engaging with a Neolithic monument in its landscape setting using GIS. Oxford Journal of Archaeology 22(4): 345-356.

Conolly, J. y M. Lake

2006 Geographical information systems in archaeology. Cambridge University Press, Cambridge.

Dalla, B.L.

1994 Methodological Considerations. Report Prepared for the Ontario Ministry of Natural Resources. Lakehead University: Center for Archaeological Resource Prediction, Thunder Bay, Ontario.

De la Torre Villar, E. y R. Navarro de Anda

1984 El Trópico Michoacano: Hombres y Tierra. Sidermex, México.

Duque Gómez, L. y J.C. Cubillos

1979 Arqueología de San Agustín. Alto de los Ídolos. Montículos y Tumbas. Fundación de Investigaciones Arqueológicas Nacionales, Banco de la República, Bogotá.

Ebert, J.I. y T. Kohler

1988 The theoretical and methodological basis of archaeological predictive Modeling. Quantifying the present and predicting the past: Theory, method, and application of archaeological predictive modeling (ed. por W.J. Judge y L. Sebastian), pp. 97-171. U.S. Government Printing Office, Washington.

Grave Tirado, L.

1997 Proyecto Carretera Uruapan-Nueva Italia. Archivo de la Dirección de Salvamento Arqueológico, Instituto Nacional de Antropología e Historia.

Grave Tirado, L. y S. Pulido Méndez

2000 Los terracalenteños: una cultura arqueológica del Postclásico en Michoacán. Antropológicas 17:87-98. IIA-UNAM, México.

Grinberg, D.M.K.

1990. Los señores del metal: Minería y metalurgia en Mesoamérica. Consejo Nacional para la Cultura y las Artes / Pangea, México.

Hosler, D.

1986 The Origins, Technology and Social Construction of Ancient West Mexican Metallurgy. Tesis doctoral, University of California, Santa Bárbara.

1988a Ancient West Mexican Metallurgy: A Technological Chronology. Journal of Field Archaeology 15: 191-217.

1988b Ancient West Mexican Metallurgy: South and Central American Origins and West Mexican Transformation. American Anthropologist 90(4): 832-856. 
1994a Arqueología y metalurgia en el Occidente de México. El bronce mesoamericano: orígenes, desarrollo y difusión, Transformaciones mayores en el Occidente de México (ed. Ávila Palafox), pp. 115-125- Universidad de Guadalajara, Guadalajara.

1994b The sounds and colours of power: The sacred metallurgical technology of ancient west Mexico. MA: MIT Press, Cambridge.

1998 Artefactos de cobre en el período Posclásico tardío mesoamericano: yacimientos minerales, regiones productivas y usos. El Occidente de México: arqueología, historia y medio ambiente. Perspectivas regionales (ed. Ávila Palafox). Universidad de Guadalajara / Instituto Francés de Investigación Científica para el Desarrollo en Cooperación.

2000 Reconocimiento de la superficie para localizar sitios de producción de cobre en la región sureste del cinturón de cobre mexicano. Reporte Instituto Nacional de Arqueologia e Historia, México. 2002 Excavaciones en el Sitio de Fundición de Cobre de El Manchón, Guerrero, México. Report Foundation for the Advancement of Mesoamerican Studies, inc.

2004 Nuevos datos sobre la producción del metal en el Occidente en la época prehispánica. Bienes estratégicos del antiguo occidente de México, Producción e intercambio (ed. por E. Williams), pp. 335-353. El Colegio de Michoacán A.C., Zamora, Michoacán.

2005 Los sonidos y colores del poder: La tecnología metalúrgica sagrada del occidente de México. Zinacantepec, Estado de México, El Colegio Mexiquense.

2009 West Mexican Metallurgy: Revisited and Revised. Journal World Prehistory 22(3): 185-212.

Johnson, J. (Ed.)

2006 Remote Sensing in Archaeology: An Explicitly North American Perspective. University of Alabama Press, Tuscaloosa, AL.

Kvamme, K.L.

1988a Using Existing Data for Model Building. Quantifying the present and predicting the past: Theory, method, and application of archaeological predictive modelling (ed. por W.J. Judge y L. Sebastian). U.S. Government Printing Office, Washington.

1988b Development and Testing of Quantitative Models. Quantifying the present and predicting the past: Theory, method, and application of archaeological predictive modelling, (ed. por W.J. Judge y L. Sebastian). U.S. Government Printing Office, Washington.

1992 A Predictive Site Location Model on the High Plains: An Example with an Independent Test. Plains Anthropologist 37(138): 19-40.

2006 There and Back Again: Revisiting Archaeological Location Modeling. GIS and Archaeological Predictive Modeling (ed. por M.W. Mehrer y K. Wescott), pp. 3-38. CRC-Taylor and Francis, Boca Raton.

Kohler, T.A.

1988 Predictive Locational Modeling: history and current practice. Quantifying the present and predicting the past: Theory, method, and application of archaeological predictive modelling (ed. por W.J. Judge y L. Sebastian). U.S. Government Printing Office, Washington.

Kohler, T.A. y S.C. Parker

1986 Predictive models for archaeological resource location. Advances in Archaeological Method and Theory (ed. por M.B. Schiffer), vol. 9, pp. 397-452. Academic Press, New York.

Lenfant, $P$.

2005. L'objet archéologique. http://www.archeologia.be/chaine-operatoire_Archeo-belga. html, (Diciembre, 2006). 
Leroi-Gourhan, A.G.

1964 Le geste et la Parole. Albin Michelle, París.

Llobera, $\mathrm{M}$.

2003 Extending GIS-based visual analysis: the concept of visualscapes. International Journal of Geographical Information Science 17: 25-48.

Maldonado, B.

2002 Modern metallurgy, prehispanic roots: coppersmithing in México. Conference SAA, Denver. 2006 Preindustrial copper production at the archaeological zone of Itziparatzico, a Tarascan location in Michoacán, México. PhD Dissertation, Pennsylvania State University.

Mendoza, O. y E. Calvillo

1982 Estudio geológico topográfico preliminar de la mina "Puerto de Mayapito", Municipio de Churumuco, Edo. de Michoacán. Consejo de Recursos Minerales, residencia Michoacán.

Michelet, D.

1995 La zona occidental en el Posclásico. Historia Antigua de México, vol. III: El horizonte Posclásico y algunos aspectos intelectuales de las culturas mesoamericanas (coord. por L. Manzanilla y L. López Luján), pp. 153-181. UNAM/INAH/Porrúa, México.

Moreno, M.V. y L. Ochoa-Landín

2006 Características metalogenéticas de los depósitos de tipo pórfido cuprífero en México y su situación en el contexto mundial. Boletín de la Sociedad de Geología Mexicana LVIII(1): 1-26.

Ottaway, B.S.

1998. The settlement as an early smelting place for copper. The Fourth International Conference on the Beginning of the Use of Metals and Alloys (Buma IV), Matsue, Shimane, Japan: The Japan Institute of Metals: 165-172.

Parcak, S.H.

2009 Satellite Remote Sensing for Archaeology. Taylor \& Francis, Londres.

Pollard, P.H.

1987 The political economy of prehispanic Tarascan metallurgy. American Antiquity 52(4): 741-752. 1993 Tariacuri's legacy, the prehispanic Tarascan state. Oklahoma University of Oklahoma Press, Norman.

1994 Factores de desarrollo en la formación del Estado Tarasco. El Michoacán Antiguo (ed. por B. Boehm de Lameiras), pp. 187-246. Zamora, El Colegio de Michoacán/ Gobierno del Estado. 1995 Estudios del surgimiento del Estado tarasco: investigaciones recientes. Arqueología del Occidente y Norte de México (ed. por E. Williams y P.C. Weigand), pp. 29-64. Zamora, El Colegio de Michoacán.

Pulido, S. y L. Grave

1997 Informe final del proyecto Carretera Pátzcuaro - Uruapan. Informe Archivo Técnico de la Coordinación Nacional de Arqueología, INAH, México.

Roskamp, $\mathrm{H}$.

1999 La historiografía indígena de Michoacán: El lienzo de Jucutacato y Los títulos de Carapan. CNWS, Leiden University. 
Roskamp, H. y M. Retíz

2001 Historia, mito y legitimación: el Lienzo de Jicalán. La Tierra Caliente de Michoacán (ed. por E. Zárate Hernández), pp. 119-151. El Colegio de Michoacán A.C., Zamora, Michoacán.

Schneider, K. y P. Robbins

2009 GIS and Moumtain Environments. Explorations in GIS Technology (Genova 1994), UNITAR Explorations in GIS Technology.

Trujillo, A.

2011 La estructura del paisaje y su influencia en la arqueología de Tierra Caliente. Raíces culturales en la Historia de La Tierra Caliente michoacana (ed. por A. Oliveros), pp. 39-63. El Colegio de Michoacán, Zamora, México.

Warren, E.R.

1990 Predictive modeling in archaeology: a primer. Interpreting Space: GIS and Archaeology (ed. por K.M. Allen, S.W. Green y E.B. Zubrow), pp. 90-111. Taylor and Francis, Londres.

Warren E.R. y D.L. Asch

2000 A predictive model of archaeological site location in the eastern Prairie peninsula. Practical applications of GIS for archaeologists: a predictive modeling toolkit (ed. por K. Wescott y J.R. Brandon), pp. 5-25. Taylor and Francis, London.

Wescott. L.K. y R.J. Brandon

2000 Practical applications of GIS for archaeologists, a predictive modeling toolkit. Taylor and Francis, Londres.

Wheatley, D. y M. Gillings

2002 Spatial technology and archaeology: archaeological applications of GIS. Taylor \& Francis, London. 
